\title{
Vibration control device for steel tubular towers of Horizontal Axis Wind Turbines
}

\author{
Douglas Mateus de Lima ${ }^{a^{*}}$ (D) \\ Pablo Aníbal López-Yánezb \\ Matheus Alves Pereira ${ }^{a}$ \\ a Núcleo de Tecnologia. Universidade Federal de Pernambuco. Caruaru-PE, Brasil. E-mail: douglasortoedro@gmail.com ${ }_{2}$ \\ matheus_alves1996@hotmail.com \\ b Departamento de Engenharia Civil. Universidade Federal de Pernambuco. Recife-PE, Brasil. E-mail: lopez.yanez@yahoo.com.br \\ * Correspoding author
}

http://dx.doi.org/10.1590/1679-78255436

\begin{abstract}
This paper presents and discusses the design of a vibration control device for a $120 \mathrm{~m}$ high steel tubular tower of onshore Horizontal Axis Wind Turbine (HAWT). The tower is modeled using beam (own code), and shell and solid finite elements (via ANSYS). The Dynamic Vibration Absorber (DVA) is designed to be attached to the tower top, aiming to analyze Tuned Mass Damper (TMD), Active Mass Damper (AMD), and Hybrid Mass Damper (HMD). The theory proposed by Den Hartog is used to determine the coefficients of the absorber and the Linear Quadratic Regulator (LQR) is applied to obtain the optimal control variables introduced by the hydraulic actuators. The HMD, the main contribuition of this paper, reaches excellent levels of vibration reduction for the tower submitted to harmonic actions, in a transient and permanent (stationary) regime, resonant to the first vibration mode of the structure without control.
\end{abstract}

\section{Keywords}

Wind turbine tower, Dynamic analysis, Vibration control, HMD.

\section{INTRODUCTION}

In the 21st century, the global water crisis and environmental issues resulted in an accelerated growth in the deployment of increasingly large onshore and offshore wind turbines, with increasingly high towers, in search of technically feasible and economically viable winds. Therefore, the technical development, trade and installation of wind turbines in the world has advanced fastly, so that the generation of energy from thermoelectric, nuclear and hydroelectric power plants has been complemented and/or replaced by the production of such equipment (Hau, 2006).

The global growth of installed wind capacity in recent years has established an annual record of 63,633 MW in 2015; resulting in a cumulative installed wind capacity of 539,581 MW at the end of 2017 (GWEC, 2018). In Brazil, wind power production reached $14.34 \mathrm{GW}$ of installed capacity in 568 wind farms and more than 7,000 wind turbines in 12 states, with the states of the Northeast Region, where the records of attendance exceed $70 \%$ of the energy produced in this region, which account for most of Brazilian production (September data according to Abeeólica, 2018). This shows that the cost of wind energy is the most competitive and viable amongst the renewable energy sources compared to the conventional ones (Burton et al., 2011 and Manwell et al., 2009).

For this reason, Brazilian political, social and technical issues have been studied in order to make feasible and further develop the use of this type of energy to produce electricity (Juárez et al., 2014). Specifically, the state of Pernambuco has carried out, over the last years, a series of actions, with the objective of fomenting the renewable energy sector (Atlas..., 2017). Among these, we highlight the attraction of industries to the Suape Wind Pole, that resulted in the 
installation of a group of companies to manufacture wind turbines, tubular towers, large blades and steel forged. For example, the wind power plants of Santa Brigida located in Caétes, Pedra and Paranatama cities of Agreste region of Pernambuco and the wind power plants of Santo Estevão in Araripina city of Chapada region of Araripe; totalizing more than 600 towers of $80 \mathrm{~m}$ high for support wind turbines in operation in the state, evidencing the growth of this type of energy.

In view of the vast potential of wind power that can be used in the state of Pernambuco, the size of the wind turbines to be used in the future tends to be increasing and more powerful, making it necessary to install these equipments under the action of more intense and continuous winds and thus causing the dimensions of the towers of these wind turbines to be continuously increased. Particularly, the height of the tower is an essential parameter for capturing stable highaltitude winds; however, the cost of this, which can exceed $20 \%$ of the wind turbine overall cost (Hau, 2006 and Yoshida, 2006), makes the height increase a disadvantage. In addition, the transport and the assembly of the tower become more expensive. Therefore, the design and installation of larger wind turbines makes it necessary to have higher and higher towers that require more elaborate structural analysis, stability and dynamics, resulting in a more complex design.

Thus, increasing the towers height, the vibration effects on the wind turbine components are greatly increased, so that in the last decades researchers and manufacturers of wind turbine components have sought solutions to mitigate the vibrations from the operation of mechanical components and wind and seismic actions (Menezes et al., 2018). Even in situations where these structures can withstand such dynamic actions, without necessarily suffering structural damage, the fatigue effects of the constituent materials should not be overlooked.

To achieve the balance between safety and economic efficiency in large wind turbine design, the structural control to mitigate excessive structure responses is a viable option. In this way, passive, active, hybrid and semi-active control systems are valuable alternatives for the control of vibrations of large wind turbine towers. Even considering the studies already carried out and the numerous practical applications of structural control in bridges, in telecommunications towers and in tall buildings, the research and application of control systems for wind turbine towers are relatively recent topics.

The use of Tuned Mass Dampers (TMD) has been the object of analysis carried out by several authors (Murtagh et al., 2008; Lackner and Rotea, 2011; Stewart and Lackner, 2013; Shzu et al., 2015; Colherinhas et al., 2015; Tong et al., 2015; and Zuo et al., 2017). However, despite the studies made, there are fields of analysis that have not yet been fully approached, such as design of a control device with satisfactory performance and with clearly demonstrated execution conditions.

Hence, this paper proposes to analyze the dynamic behavior and design of a vibration control device for a $120 \mathrm{~m}$ high steel tubular tower of a 3.2 MW Horizontal Axis Wind Turbine (HAWT). Thus, the Hybrid Mass Damper (HMD), proposed in this research, is presented as a differentiated solution to the previously mentioned studies, since, instead of being allocated to the nacelle ( $\mathrm{Hu}$ and $\mathrm{He}, 2017$ ), it was designed to be installed internally to the wind turbine tower (near the top). In this way, the internal space of the nacelle is saved for the installation of the electric-mechanical components of the wind turbine (Zuo et al., 2017). This has the advantage of facilitating access to the control equipment, contributing to improve the maintenance conditions.

The insensitivity to orientation (Stewart and Lackner, 2014), combined with the restrained displacement of the HMD, suggests that it could just as effectively be located at the top of the tower rather than in the nacelle, which may be more convenient, because the HMD would not yaw with the nacelle. It would essentially experience all orientations, which does not appear to impact the load reductions.

It is also highlighted the development of constructive model of the DVA developed, in which its main components are described, in order to show the viability of design and execution of the vibration control system designed for the tower analyzed.

\section{VIBRATION CONTROL THEORY}

\subsection{Passive control vibration}

For the vibration control methodology used in this paper, the theoretical development of the TMD proposed by Den Hartog (1947) was initially used for systems with two degrees of freedom, one of which is necessary to describe the movement of the main mass (the structure to be controlled) and the second one referring to the secondary mass (mass of the vibration absorber). The TMD is a device consisting of a mass, a spring (or a combination of springs) and a damper (or a damper assembly) that are attached to the main structure in order to reduce/control its dynamic response. The frequency of the absorber is tuned in a certain frequency of the main structure. When this frequency is excited, the 
absorber vibrates out of phase in relation to the movement of the structure, dissipating the energy contained in the main structure by the movement of the absorber.

The absorber parameters (mass $m_{t}$, stiffness $k_{t}$, and damping $c_{t}$ ) will be determined according to their design requirements (frequency tuning of the absorber). The main structure is represented by its modal parameters (mass $m_{p}$ , stiffness $k_{p}$, and damping $c_{p}$ ) referring to the mode of vibration that will be controlled. It should be noted that the TMD theory was applied to a non-damped main structure, considering the low structural damping of the tower studied here (damping ratio of $0.8 \%$, as indicated by Brazilian Standard ABNT, 1988 and Blevins, 2001).

Writing the motion equations of the system and applying the complex numbers for resolution when the main structure is subjected to a harmonic excitation, we obtain:

$a_{p}=a_{e s t}\left[\frac{\left(\beta^{2}-f^{2}\right)^{2}+(2 \zeta \beta)^{2}}{(2 \zeta \beta)^{2}\left(\beta^{2}-1+\mu \beta^{2}\right)^{2}+\left[\mu f^{2} \beta^{2}-\left(\beta^{2}-1\right)\left(\beta^{2}-f^{2}\right)\right]^{2}}\right]^{\frac{1}{2}}$

which is the steady-state amplitude of the mass $m_{p}$, and

$a_{t}=a_{e s t}\left[\frac{f^{4}+(2 \zeta \beta)^{2}}{(2 \zeta \beta)^{2}\left(\beta^{2}-1+\mu \beta^{2}\right)^{2}+\left[\mu f^{2} \beta^{2}-\left(\beta^{2}-1\right)\left(\beta^{2}-f^{2}\right)\right]^{2}}\right]^{\frac{1}{2}}$

which is the steady-state amplitude of the mass $m_{t}$ (Rao, 2011). Where: $\mu$ is the mass ratio between the absorber and main mass:

$\mu=\frac{m_{t}}{m_{p}}$

$f$ is the ratio of square angular frequency of the absorber and main mass:

$f=\frac{\omega_{t}}{\omega_{p}}$

$\beta$ is the ratio between the angular frequencies of the exicitacion $(\bar{\omega})$ and main mass:

$\beta=\frac{\bar{\omega}}{\omega_{p}}$

$a_{e s t}$ is the static defletion of the main system, Equation (6), and $\zeta$ is the damping ratio of the vibration absorber, according to Equation (7).

$a_{\text {est }}=\frac{F_{0}}{k_{p}}$

which, $F_{0}$ is the amplitude of the proposed harmonic excitation. 
$\zeta=\frac{c_{t}}{c_{c}}(7)$

where, $c_{c}$ is the "critical" damping constant, given by:

$c_{c}=2 m_{t} \omega_{p}$

With the addition of the absorber to the system, it is intended to reduce the amplitude peaks of the main mass to the lowest possible values. The amplitude peaks of the main structure are infinite when the damping of the absorber is zero (resonance) or infinite. However, there is an intermediate value of damping for which these peaks are minimal, since the work performed by the damping force is maximum.

According to Den Hartog (1947), by evaluating the values $\beta$ in Equation (1), the amplitude of the main mass becomes independent of $\zeta$ (in the two fixed points of the graph $a_{p}$ versus $\beta$ ) when:

$$
f=\frac{1}{1+\mu}
$$

which is the tuning required as a function of the absorber mass.

Finally, the optimal damping values can be calculated by substituting (9) into (1), deriving the resulting expression from $\beta$ and equating to zero to have horizontal tangents at fixed points. Therefore, after long algebraic work and taking a convenient average value of the optimal fixed points of damping, we obtain:

$$
\zeta_{\text {optimun }}^{\text {medium }}=\left[\frac{3 \mu}{8(1+\mu)^{3}}\right]^{\frac{1}{2}}
$$

Thus, by using the damping value above, there is an almost horizontal tangent at each of the fixed points. The stiffness value of the tuned absorber can be calculated using Equations ( 3 ) and (4):

$$
k_{t}=f^{2} k_{p} \mu
$$

The design values of the vibration absorber coefficients are calculated by considering that the tower movement is governed predominantly but independently by the first two natural modes of vibration (the first two flexural modes having practically equal vibration frequencies). Thus, the absorber is independently tuned to the two natural frequencies whose modes define movements according to the first two vibration modes of the tower. The optimal values of the absorber coefficients are then obtained as if these two modes of vibration of the tower were represented by two independent systems of one degree of freedom (dof) each, in order to make feasible the application of Den Hartog's theory.

The TMD is preferably allocated where the deflections of the structure are larger; in this case, the TMD motion is associated with an added translational dof near the tower top. Thus, the mass, stiffness, and damping matrices of the coupled system (tower-absorber) come from the addition of the aforementioned dof.

Therefore, by means of the modal mass, stiffness, and damping values, the coefficients corresponding to the modes of vibration of the main system to be controlled are obtained. Then, starting from the choice of mass ratio $\mu$, the stiffness and damping of the absorber are obtained in two directions transverse to the tower and perpendicular to each other (Figure 1a). It is pointed out that if the actuating excitation does not coincide with the direction of any of the axes where the stiffnes and damping of the absorber are arranged, there will be the vectorial combination thereof for the stiffness and damping resulting from the passive controller in any direction of the cross-section of the tower. 

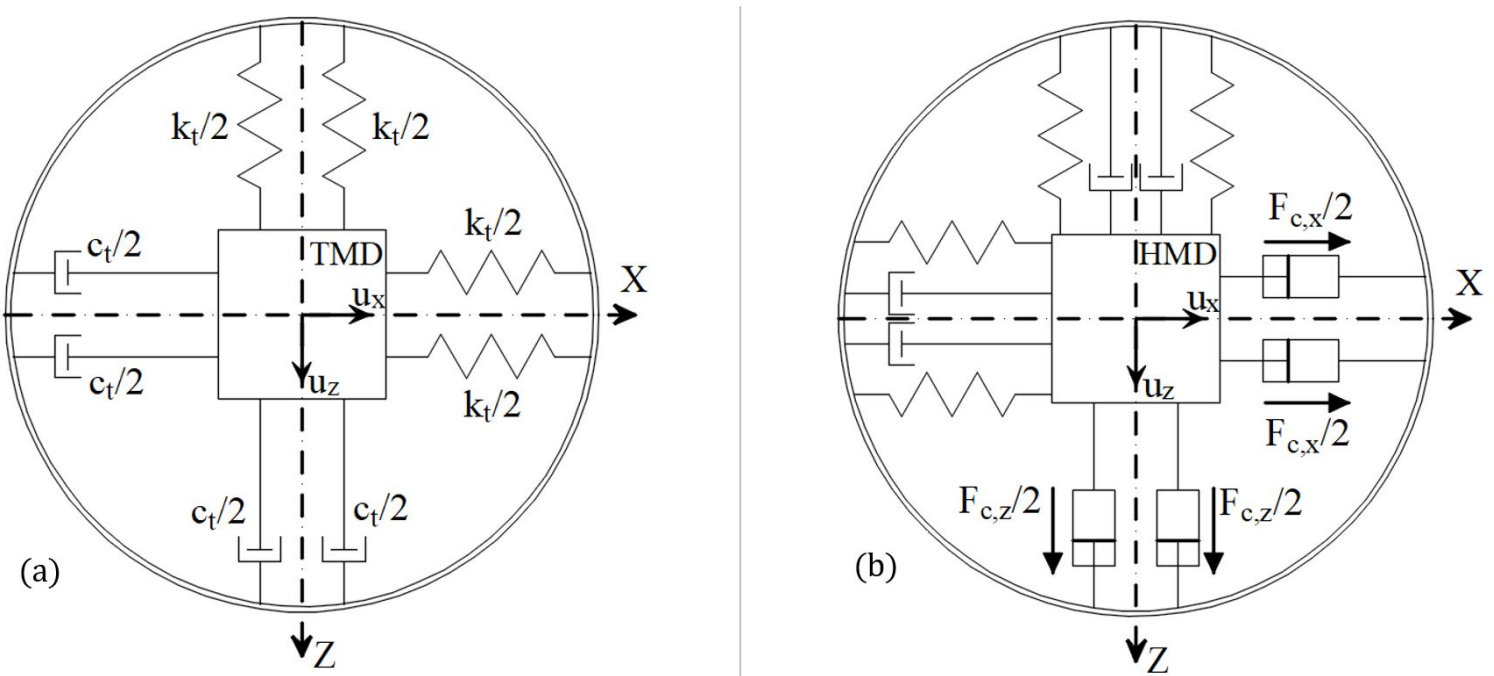

Figure 1: Schemes of passive (a) and hybrid (b) Dynamic Vibration Absorbers (DVA) with two degrees of freedom.

\subsection{Hybrid vibration control}

The translational hybrid vibration absorber of two degrees (Figure 1b) is defined similarly to the dynamic passive vibration absorber with two degrees of freedom of translation. Hydraulic actuators were added to the system in order to convert the TMD into a Hybrid Mass Damper (HMD), which is applied to the tower top to obtain a hybrid control system.

This model is idealized as part of a full state feedback control system, that is, the actuators apply forces of magnitudes and directions pre-established by the controller. These forces are generated from the signals received from the sensors positioned in a way measure all model state variables. Thus, for a tower model with 8 beam finite elements that already shows good accuracy in relation to the structure of the excessively discrete tower, with respect to the most significant global vibration modes for dynamic final tower response, it is necessary to position the sensors every $15 \mathrm{~m}$ of tower length, for example.

Working in the field of analysis and design of modern control systems, it is convenient to represent the differential equations that generate the movement of a dynamic system in the states space (Moutinho, 2007). This analysis involves three types of variables in its modeling, namely: state variables, input variables and output variables. The state variables of a dynamic system are quantities whose set of values determines the state of the system (Junkins and Kim, 1993). Input variables are quantities related to external actions or control forces/moments applied to the structure. The output variables are related to the input or state variables that can be measured, since in many practical situations, not all states or inputs are available for measurement.

Considering the static condensation (Clough and Penzien, 2003; Chopra, 2012 and Humar, 2002) of the dynamic system that represents the behavior of the tower, in order to dynamically study the horizontal translation dof, the dynamic motion equation of the structure-DVA takes the following form:

$$
\left[\widetilde{M}_{u}\right]\{\ddot{\tilde{u}}\}+\left[\widetilde{C}_{u}\right]\{\dot{\tilde{u}}\}+\left[\widetilde{K}_{u}\right]\{\tilde{u}\}=[\bar{J}]\left\{\tilde{F}_{u}\right\}+\left[\bar{J}_{c}\right]\left\{\bar{F}_{c}\right\}
$$

where: $\left[\widetilde{M}_{u}\right],\left[\widetilde{C}_{u}\right]$, and $\left[\widetilde{K}_{u}\right]$ are, respectively, the mass, damping and stiffness matrices in relation to the horizontal translation dof of the tower-absorber assembly, dimension $\left[\left(n_{c}+r_{c}\right),\left(n_{c}+r_{c}\right)\right] ;\{\tilde{u}\}$ is the translational displacements vector, order $\left(n_{c}+r_{c}\right) ;\left\{\tilde{F}_{u}\right\}$ is the vector of external forces, order $m_{c} ;[\bar{J}]$ is the positioning matrix of external forces, dimension $\left[\left(n_{c}+r_{c}\right), m_{c}\right]$, which, in this case, is an identity matrix, because the forces act in all horizontal translation dof; $\left\{\bar{F}_{c}\right\}$ is the vector of control forces, order $r_{c} ;\left[\bar{J}_{c}\right]$ is the positioning matrix of control forces, dimension $\left[\left(n_{c}+r_{c}\right), r_{c}\right] ; n_{c}$ represents the number of horizontal dof of the condensed system without absorber; $m_{c}$ represents the number of horizontal external forces applied; $r_{c}$ represents the number of horizontal control forces of the actuator 
according to the degree of freedom of the vibration absorber; and, consequently, $\left(n_{c}+r_{c}\right)$ represents the number of horizontal translations dof of the tower-absorber assembly.

In the hybrid vibration absorber is considered that external forces are not applied, but only a control force imposed by the actuator. Thus, the vector $\left\{\tilde{F}_{u}\right\}$ takes the following form:

$\left\{\tilde{F}_{u}\right\}=\left\{\begin{array}{c}\tilde{F}_{u 1} \\ \tilde{F}_{u 2} \\ \vdots \\ \tilde{F}_{u n_{c}} \\ 0\end{array}\right\}$

the control force vector $\left(r_{c}=1\right)$ is:

$$
\left\{\bar{F}_{c}\right\}=\bar{F}_{c}
$$

and the matrix $\left[\bar{J}_{c}\right]$ is given by:

$$
\left[\bar{J}_{c}\right]=\left[\begin{array}{c}
{[0]_{\left(n_{c}+r_{c}-2\right), 1}} \\
-1 \\
1
\end{array}\right]
$$

in which, terms 1 and -1 refer to the action and reaction, from the control force applied by the actuator to the absorber and the respective reaction in the tower where the actuator is attached, respectively.

Finally, for passing to the state space, we isolate the vector $\{\ddot{\widetilde{u}}\}$ from Equation (12) and define the vector of state variables $\{X\}$, order $2\left(n_{c}+r_{c}\right)$, given by:

$$
\{X\}=\left\{\begin{array}{l}
\{\tilde{u}\} \\
\{\dot{\tilde{u}}\}
\end{array}\right\}
$$

obtaining the STATE EQUATION of the system:

$$
\{\dot{X}\}=[A]\{X\}+[B]\left\{\tilde{F}_{u}\right\}+\left[B_{c}\right]\left\{\bar{F}_{c}\right\}
$$

which will be solved by applying a linear transformation diagonalizing the state matrix $[A]$ :

$$
[A]=\left[\begin{array}{cc}
{[0]} & {[I]} \\
-\left[\widetilde{M}_{u}\right]^{-1}\left[\widetilde{K}_{u}\right] & -\left[\widetilde{M}_{u}\right]^{-1}\left[\widetilde{C}_{u}\right]
\end{array}\right]
$$

$[B]$ is the input matrix of the external forces applied to the horizontal translation dof:

$$
[B]=\left[\begin{array}{c}
{[0]} \\
{\left[\widetilde{M}_{u}\right]^{-1}[\bar{J}]}
\end{array}\right]
$$


and, $\left[B_{c}\right]$ is the input matrix of the control forces applied to the vibration absorber:

$$
\left[B_{c}\right]=\left[\begin{array}{c}
{[0]} \\
{\left[\widetilde{M}_{u}\right]^{-1}\left[\bar{J}_{c}\right]}
\end{array}\right]
$$

Finally, we have the output equation that defines the output vector $\{Y Y\}$ of the system as a linear combination of the state variables and the control input variables:

$$
\{Y Y\}=[C C]\{X\}+[D D]\left\{\bar{F}_{c}\right\}
$$

where: $[C C]$ is the output matrix that determines the relationship between the state system and the output system; $[D D]$ is the feed-forward matrix; and, $p_{c}$ represents the number of output variables.

\subsection{Active vibration control}

An Active Mass Damper (AMD) was implemented to evaluate the behavior of the system controlled by a purely active absorber and to have information of the energy expenditure necessary to perform the control of the tower by this type of absorber. The AMD of two degrees of freedom consists of a system composed of a mass guided exclusively by hydraulic actuators, without springs and dampers. Thus, from the HMD, the stiffness and damping matrices are obtained by assigning null values to the parameters of stiffness and damping of the absorber (that is, $k_{t}=0$ and $c_{t}=0$ ). The mass matrix remains unchanged from the hybrid system, depending only on the mass ratio $\mu$. In addition, the external and control forces vectors have the same format as those in Equations (14) and (15), respectively.

\subsection{Linear optimal control}

In active and hybrid control systems is necessary to determine the values of the input variables that will be applied by the actuators. In this way, the design of stable control systems based on quadratic performance indexes (or cost function) will be considered in this item. We intend to choose the control vector $\left\{\bar{F}_{c}\right\}$ such that a given performance index is minimized. Thus, a quadratic performance index $J$, where the limits of integration are 0 and $\infty$, is given by:

$J=\int_{0}^{\infty} L\left(\{X\},\left\{\bar{F}_{c}\right\}\right) d t$

where $L\left(\{X\},\left\{\bar{F}_{c}\right\}\right)$ is a quadratic function that leads to linear control laws (Meirovitch, 1990):

$$
\left\{\bar{F}_{c}\right\}=-[K G]\{X\}
$$

where $[K G]$ is the optimal feedback gain matrix, dimension $\left[r_{c}, 2\left(n_{c}+r_{c}\right)\right]$, of the optimal control vector. The design of optimum control systems, based on quadratic performance indexes, is reduced to the determination of matrix elements. The performance index for the control system is:

$J=\int_{0}^{\infty}\left(\{X\}^{T}[Q]\{X\}+\left\{\bar{F}_{c}\right\}^{T}[R]\left\{\bar{F}_{c}\right\}\right) d t$

where: $[Q]$ is the state ponderation matrix, which is positive-(semi)definite real symmetric for systems with real matrices and vectors, dimension $\left[2\left(n_{c}+r_{c}\right), 2\left(n_{c}+r_{c}\right)\right] ;[R]$ is the control ponderation matrix, which is positive- 
definite real symmetric for systems with real matrices and vectors, dimension $\left[r_{c}, r_{c}\right]$. The control forces vector $\left\{\bar{F}_{c}\right\}$ is unconstrained, except those of a practical interest.

The second term on the right-hand side of Equation (24) accounts for the energy expenditure of the control signals, which will be a determining factor for the operation of the control system, because the intensity of the control force will be limited by the capacity of the hydraulic actuators.

To solve the optimization problem, we substitute (23) into (17):

$$
\{\dot{X}\}=\left([A]-\left[B_{c}\right][K G]\right)\{X\}+[B]\left\{\tilde{F}_{u}\right\}
$$

in which, we assume that the matrix $\left([A]-\left[B_{c}\right][K G]\right)$ is stable, or that its eigenvalues have negative real parts. Substituing Equation (23) into (24):

$J=\int_{0}^{\infty}\{X\}^{T}\left([Q]+[K G]^{T}[R][K G]\right)\{X\} d t$

According to Ogata (1997), we use the Lyapunov approach to solve this optimization problem:

$$
\{X\}^{T}\left([Q]+[K G]^{T}[R][K G]\right)\{X\}=-\frac{d}{d t}\left(\{X\}^{T}[P]\{X\}\right)
$$

where $[P]$ is positive-definite real symmetric matrix (real parameters). Developing the equation above:

$$
\{X\}^{T}\left([Q]+[K G]^{T}[R][K G]\right)\{X\}=-\{\dot{X}\}^{T}[P]\{X\}-\{X\}^{T}[P]\{\dot{X}\}
$$

replacing Equation (26) without the vector of external forces that may be associated with external disturbances acting on the system, and observing that this equation must be true for any $\{X\}$, we obtain:

$$
\left([A]-\left[B_{c}\right][K G]\right)^{T}[P]+[P]\left([A]-\left[B_{c}\right][K G]\right)=-\left([Q]+[K G]^{T}[R][K G]\right)
$$

By Lyapunov's second method (Lyapunov, 1992), if $\left([A]-\left[B_{c}\right][K G]\right)$ is a stable matrix, thus there is a $[P]$ positive-definite matrix that satisfies Equation (29). Therefore, the procedure to be followed is to determine the $[P]$ elements of and verify whether it is positive definite.

In order to obtain the solution to the quadratic optimal control problem, we write the matrix $[R]$ as:

$$
[R]=[T]^{T}[T]
$$

where $[T]$ is a nonsingular matrix. Then, Equation (29) can be rewritten and then minimized the quadratic form below that is required in the case of minimization of $J$ with respect to $[K G]$ :

$$
\{X\}^{T}\left[[T][K G]-\left([T]^{T}\right)^{-1}\left[B_{c}\right]^{T}[P]\right]^{T}\left[[T][K G]-\left([T]^{T}\right)^{-1}\left[B_{c}\right]^{T}[P]\right]\{X\}
$$

a function of $[K G]$. Since this last expression is nonnegative, the minimum occurs when it is zero. Thus: 


$$
[K G]=[R]^{-1}\left[B_{c}\right]^{T}[P]
$$

which is the optimal gain matrix required. Finally, the $[P]$ matrix from the above expression must satisfy the following expression based on Equation (29):

$$
[A]^{T}[P]+[P][A]-[P]\left[B_{c}\right][R]^{-1}\left[B_{c}\right]^{T}[P]+[Q]=[0]
$$

that is called the matrix Ricatti equation. Its resolution is obtained by the process of diagonalization, as presented in Kwakernaak and Sivan (1972).

\section{TOWER MODELING}

A S355J2 steel tubular tower (design by Lima et al., 2018; Figure 2) supporting an SWT-3.2-113 (Siemens, 2014) wind turbune was considered, according to the characteristics specified in Table 1.

Table 1: Parameters of the wind turbine manufacturer (Siemens, 2014).

\begin{tabular}{cc}
\hline & Parameters \\
\hline IEC (International Electrotechnical Commission) Class & IIA \\
Rated power (MW) & 3.2 \\
Rotor diameter (m) & 113.0 \\
Blade length (m) & 55.0 \\
Swept area ( $\left.\mathrm{m}^{2}\right)$ & 10,000 \\
Hub height (m) & $79.5-142.0$ (used $122.5 \mathrm{~m}$ ) \\
Power regulation & Pitch regulated \\
Annual output at $8.5 \mathrm{~m} / \mathrm{s}$ & $14,402 \mathrm{MWh}$ \\
Nacelle weight (ton) & 78 \\
Rotor weight (ton) & 67 \\
\hline
\end{tabular}

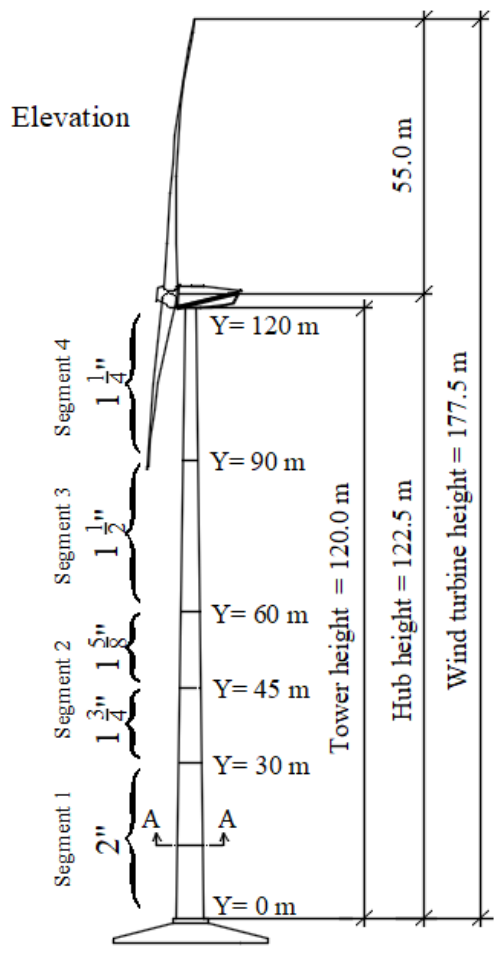

Section A-A: typical cross section

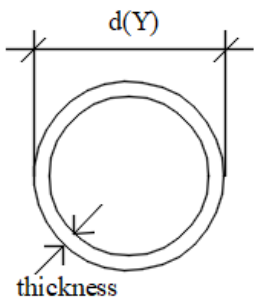

Circular slab footing: section (m)

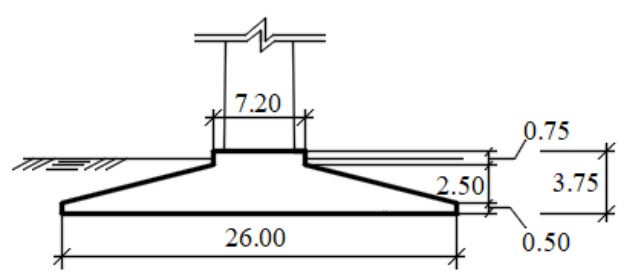

Figure 2: Tower-foundation design, off-scale (Lima et al., 2018). 
The modeling of the tower was done using the Finite Element Method - MEF (Cook et al., 2002), considering nonlinear geometric elastic behavior. Initially, a code was implemented in Mathcad v.15 (Mathcad, 2012), in which the tower was modeled as a structure clamped at the base and free at the top (cantilevered), using 8 dof beam finite elements (4 dof per node: axial and transverse translations, flexional and torsional rotations). An analysis was made of the required level of discretization (convergence analysis). It was noticed that a discretization with about 16 beam elements is already sufficiently accurate to the modal analysis necessary for the design of the control device proposed.

Moreover, a finite element model was created in the software ANSYS r.14.5 (2012), in which the tower was also clamped in the base (Figure 3a) and discretized by 7272 shell elements with 4 node and 6 dof per node (Figure 3b). The nacelle was modeled with tetrahedral solid finite elements, designated by SOLID187 (Figure 3c), with 10 nodes and 3 translational dof per node; representing it by a uniform mass. The main reason that led to the use of two finite element models was the need to evaluate the reliability and accuracy of the numerical results obtained.

The results of the modal analysis performed by Lima (2018) for both the shell and beam finite element model are similar for the global vibration modes, mainly with respect to the 1st mode of vibration of the tower that is more susceptible to excitation. Therefore, the beam FE model can be used as a representative of the dynamic behavior of the tower when it is subjected to the harmonic excitations resonant to its fundamental frequency.
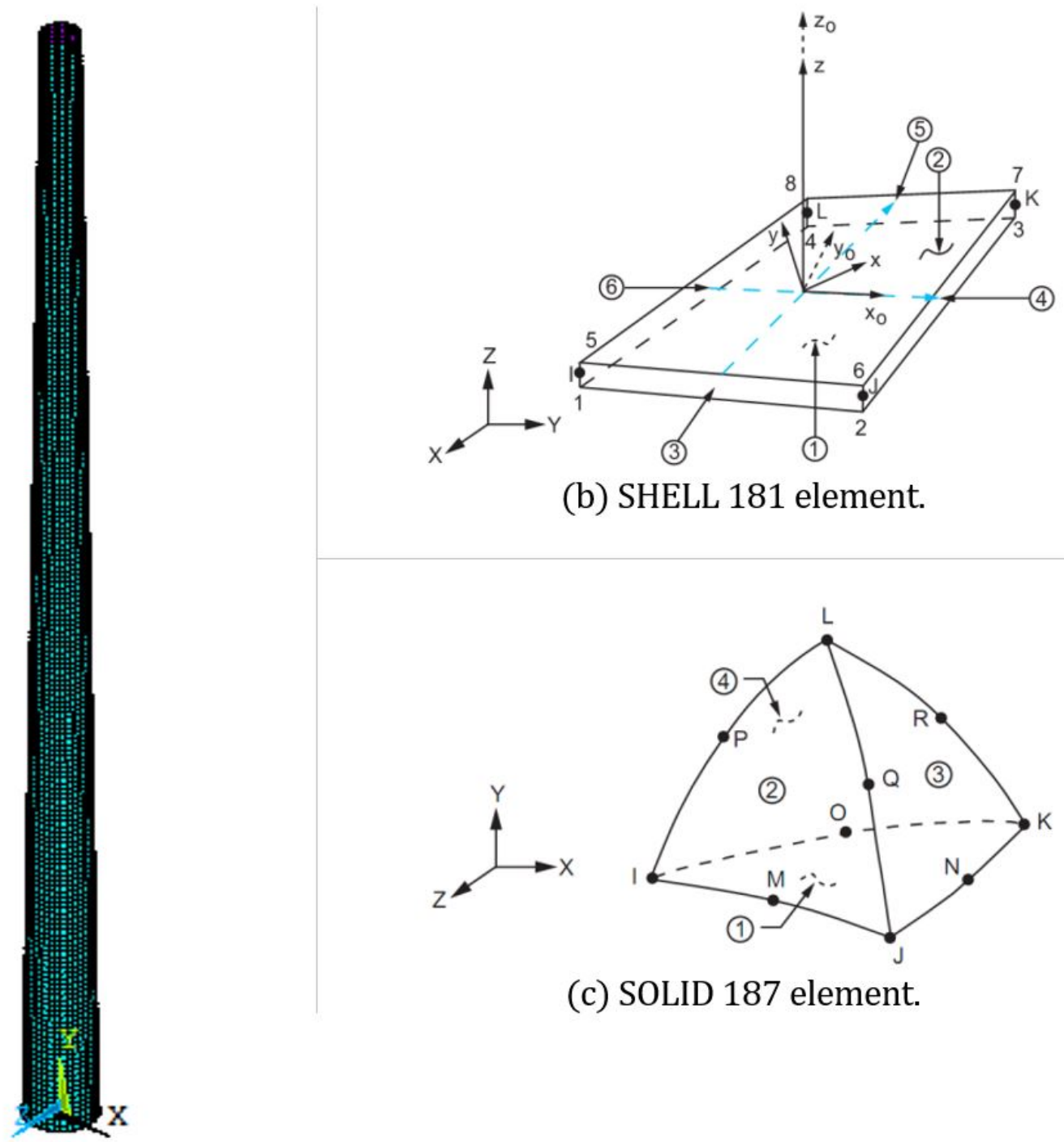

(b) SHELL 181 element.

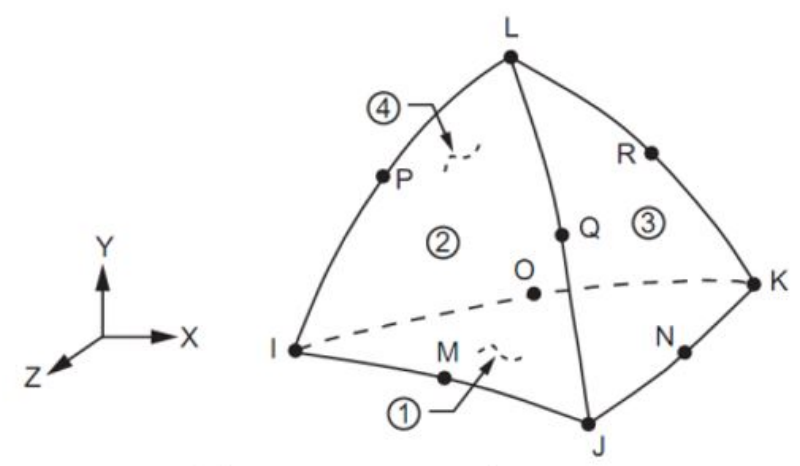

(c) SOLID 187 element.

(a) FE tower model.

Figure 3: Model and finite elements used.

For excitation modeling, the terms amplitudes of the vector of forces applied horizontally to the tower were calculated using the parameters established by ABNT (1988): fluctuating component of the wind was established 
according to the difference between the peak velocity pressure and the main velocity pressure; and a horizontal force from the nacelle-rotor system applied to the top of the tower (according to Asibor et al., 2015).

The fluctuating component of the wind and the horizontal force transmitted by the rotor to the top were adopted according to a harmonic excitation considered resonant to the fundamental mode of vibration of the tower. In this way, it was considered that the tower vibrates around the equilibrium position determined by the action coming from the main wind speed (Franco, 1993). The amplitude of the force applied to the tower top has an order of magnitude 100 times greater than the other amplitudes that corroborates with the excitation of its fundamental mode. It is also commented that the random effect of the wind action in the determination of the force vector was not considered, but only the intensity of the wind action that corresponds to its fluctuating component (wind gusts).

\section{ANALYSIS AND RESULTS}

\subsection{Passive vibration control of tower}

In order to design a dynamic vibration absorber with two degrees of freedom that is able to control the oscillations according to the lateral directions $X$ and $Z$, it is assumed that the movement according to the direction $X$ of the tower is governed by the first mode of vibration (1st flexional mode in the XY-plane) and that the movement according to the $Z$ direction is governed by the second mode (1st flexional mode in the YZ-plane). This fact is possible because it is a symmetrical structure, resulting in the first non-coupled modes of vibration (flexional XY and YZ). Thus, the absorber is designed to directly control the first two flexural modes of vibration of the tower, but having its utility directed to the control of the tower as a whole, since the vectorial composition of the stiffness and damping of the absorber allows the control in any direction transverse to the tower. Moreover, exclusively for the purposes of designing the absorber, the modal dampings associated with the 1st vibration modes of the tower are neglected in order to allow the application of Den Hartog's theory.

The modal mass and stiffness from the 1st tower vibration modes are given in Table 2. For the design of the absorber, the mass of the DVA is equal to $3 \%$ of the total mass of the tower (that is equal to $8.534 \mathrm{E} 5 \mathrm{~kg}$ ), differently than some authors suggest that it is 0.5 to $1.0 \%$ (Housner et al., 1997). The tower is a large structure, so a greater mass percentage is needed to attenuate its vibrations without there being an amplitude of displacement exacerbated of the DVA, because there is a space limitation at the top of the tower (the top diameter of the analyzed model is $3.5 \mathrm{~m}$ ). Thus, the DVA mass was adjusted in order to maintain its vibration amplitude limited to the space within the tubular structure of the tower.

With the values of the modal mass of the tower and the mass of the absorber, the parameters $\mu(18.651 \%)$ and $f$ (0.843), respectively, are determined using Equations (3) and (4). Applying these values and the modal stiffness to Equation (11), the stiffness required for the absorber is obtained. Finally, the damping constant is calculated by Equations (7), (8), and (10). Table 2 shows the values of the vibration absorber parameters valid for both the $X$ and $Z$ directions.

Table 2: Modal parameters for the DVA design.

\begin{tabular}{|c|c|c|c|}
\hline Structure type & Mass (kg) & Stiffness (N/m) & Damping (kg/s) \\
\hline Tower & $1.37263 \mathrm{E} 5$ & $4.79351 \mathrm{E} 5$ & - \\
\hline DVA & 2.56014 E4 & 6.35067 E4 & 1.95797 E4 \\
\hline
\end{tabular}

The absorber mass of $25601.4 \mathrm{~kg}$ is composed of a steel box $(1.00 \times 1.00 \times 2.25 \mathrm{~m})$ filled with lead. Lead was used as fill material because of its high specific mass $\left(11340 \mathrm{~kg} / \mathrm{m}^{3}\right)$ and, consequently, reduction of the volume of the control device. Thus, given the parameters of the vibration absorber, the stiffness, mass, and damping matrices of the vibrationcoupled tower-absorber system are assembled.

From the spectral matrix $[\Lambda]$ of the state matrix $[A]$, we obtain the angular frequencies of the tower-absorber system, via the representation of poles in the complex plane (root locus method). In fact, the value of each pole is directly related to the dynamic characteristics of the corresponding vibration mode. Thus, using the root locus method, it is possible to evaluate the modifications imposed on the structure in terms of the natural frequencies and the damping coefficients. The main frequencies and the types of global vibration modes of the tower-DVA system are shown in Figure 4. 


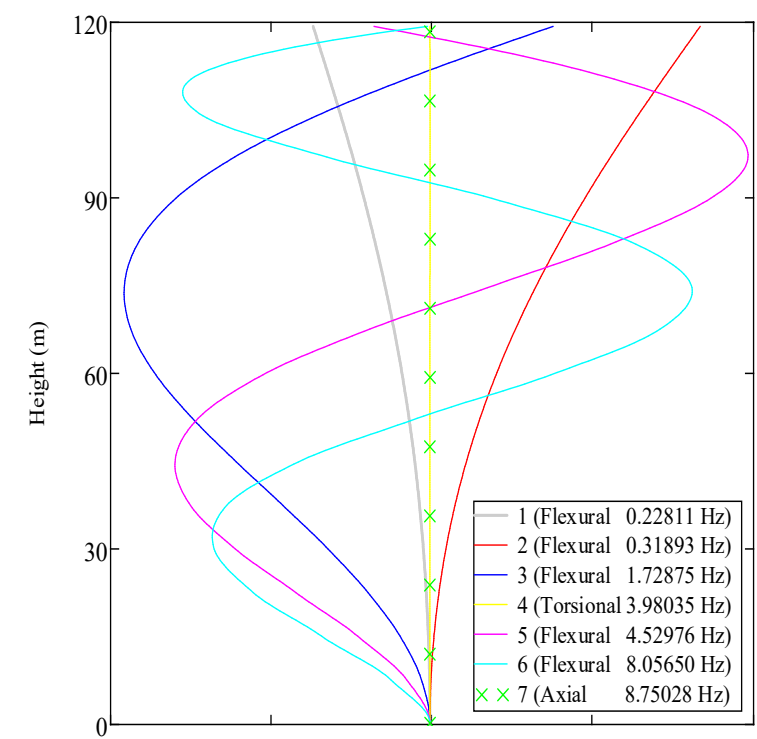

Figure 4: Normalizaded modes of vibration (displacements transverse to the tower).

The function of the passive vibration absorber is to detune the fundamental frequency of the tower with respect to the proposed excitation frequency, since the fundamental frequency of the tower without vibration absorber, which is equal to $0.29745 \mathrm{~Hz}$, becomes be equal to $0.22810 \mathrm{~Hz}$, for the case of the tower-DVA assembly. In addition, the 2nd vibration frequency $(0.31889 \mathrm{~Hz})$ is slightly higher than the fundamental frequency of the tower without absorber. However, such detuning is done by reducing the natural frequency of the structure, i.e., leaving the tower even more flexible. This low flexibility of the tower has been the subject of research that seeks to develop the so-called soft towers, in order to make them more competitive solutions in the market, since, great savings could be reached in case the dogma of great distances between eigenfrequency and exciting frequency is disregarded (Lange and Elberg, 2018).

\subsection{Hybrid vibration control of tower}

It is possible to improve the dynamic behavior of the tower (to reduce the intensity and number of vibration cycles) when implementing the hybrid vibration control. Thus, with the passive vibration absorber being designed for the two translational degrees of freedom according to the $X$ and $Z$ directions, the same parameters for the dynamic hybrid vibration absorber are used and the design is complemented with the determination of the optimal control variables to be introduced by the hydraulic actuators.

For the determination of the system state feedback gain matrix $[K G]$, Equation (32), it is necessary to solve the matrix equation of Ricatti, Equation (33), to obtain the matrix $[P]$. For this, the matrices of state ponderation $[Q]$ and control ponderation $[R]$ of the system were obtained through an analysis process about: required control (amplitude of displacements and velocities of the controlled tower); energy expended to perform this control (intensity of control forces imposed by the hydraulic actuators); building (dimensions for the vibration absorber and range of stiffness and damping constants found on the market, for springs and viscous dampers); and operability and maintenance (range of displacement amplitudes and velocities of the control device, so as to allow the operation of this within the tower, such as, for example, the limitation of displacement as a function of the space at the top of the tower for electrical and safety equipments and movement of the absorber).

The control ponderation $[R]$ matrix was taken equal to the identity matrix. The state ponderation $[Q]$ matrix was initially taken from the order identity matrix and after adjustments made according to the reasons explained in the previous paragraph: $Q_{\frac{N}{2}-1, \frac{N}{2}-1}=10^{12}$ (ponderation element of the top of the tower displacement) and $Q_{\frac{N}{2}, \frac{N}{2}}=10^{10}$ (ponderation element of the DVA displacement).

\subsection{Active vibration control of tower}

The procedure for obtaining the gain matrix $[K G]$ of the system for active control is identical to the hybrid system, and the same $[Q]$ state and $[R]$ control ponderation matrices are used. However, in the state matrix $[A]$ containing the 
damping and stiffness matrices, the damping and stiffness absorber coefficients are zero, since there are no springs or dampers in the active control system (there are only hydraulic actuators). The mass matrix of the tower-DVA coupled system remains the same.

\subsection{Parametric analysis of control systems}

In order to compare the performances of the passive, hybrid and active control systems, simulations were made of the response of the controlled tower, the output of the vibration absorber and the control forces as a function of the mass ratio $(\bar{\mu})$, which is the mass ratio of the absorber vibration and overall structure.

For plotting the graphs presented, the mass ratio was varied and the other parameters of the absorber, such as stiffness and damping, were recalculated for each mass ratio value, in order to maintain the tuning of the frequency of the absorber with the frequency of the tower, according to Table 3.

Table 3: Parametric analysis of control systems.

\begin{tabular}{|c|c|c|c|c|}
\hline $\begin{array}{c}\text { Mass ratio } \\
\bar{\mu} \text { (\%) }\end{array}$ & Modal mass ratio $\mu$ (\%) & Frequency ratio $f$ & $\begin{array}{c}\text { DVA stiffness } \\
k_{t}(\mathbf{N} / \mathbf{m})\end{array}$ & $\begin{array}{c}\text { DVA damping } \\
c_{t}(\mathrm{~kg} / \mathrm{s})\end{array}$ \\
\hline 1.0 & 6.217 & 0.941 & 2.64153 E4 & 4.44880 E3 \\
\hline 2.0 & 12.434 & 0.889 & 4.71495 E4 & 1.15540 E4 \\
\hline 3.0 & 18.651 & 0.843 & 6.35067 E4 & 1.95797 E4 \\
\hline 4.0 & 24.869 & 0.801 & 7.64536 E4 & 2.79219 E4 \\
\hline 5.0 & 31.086 & 0.763 & 8.67169 E4 & 3.62791 E4 \\
\hline 7.5 & 46.629 & 0.682 & 1.03960 E5 & 5.63376 E4 \\
\hline 10.0 & 62.171 & 0.617 & 1.13317 E5 & 7.45715 E4 \\
\hline 12.5 & 77.714 & 0.563 & 1.17953 E5 & 9.08481 E4 \\
\hline 15.0 & 93.257 & 0.517 & 1.19692 E5 & 1.05310 E5 \\
\hline 17.5 & 108.800 & 0.479 & 1.19625 E5 & 1.18167 E5 \\
\hline 20.0 & 124.343 & 0.446 & 1.18427 E5 & 1.29632 E5 \\
\hline
\end{tabular}

In the graph shown in Figure 5a, the modal mass ratio $\mu$ increases linearly with the mass ratio $\bar{\mu}$; and the ratio $f$ between the angular frequencies is inversely proportional to the mass ratio $\mu$, which is the expression for the required tuning of the absorber under optimum conditions according to Den Hartog's theory. Figure 5b shows an increasing DVA stiffness up to a maximum value (1.19692 E5 N/m) around the value of $15 \%$ of the mass ratio, from which the stiffness decreases slightly. In addition, an almost linear DVA damping behavior is observed as the mass ratio is increased.
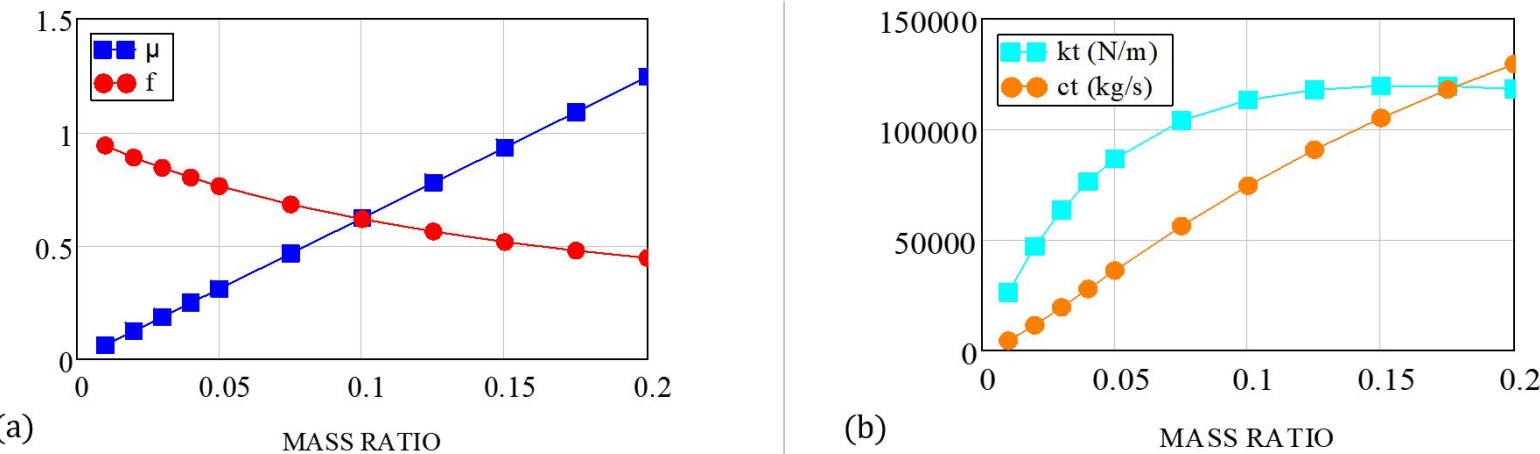

Figure 5: Graphs of: (a) $\mu$ and $f$ versus $\bar{\mu}$; (b) $k_{t}$ and $c_{t}$ versus $\bar{\mu}$.

In Figure 6a is shown the graph of the displacement r.m.s. (root mean square) ratio between the values of the tower top controlled and without control, for the three types of control studied (purely passive, hybrid and purely active), as a function of mass ratio $\bar{\mu}$. As expected, hybrid, active and passive control systems require, in this order, a smaller amount of DVA-mass to achieve the same level of control. For example, at a mass ratio of 0.03 , the passive system reduces the 
displacement r.m.s. from the top of the controlled tower to a value that is equivalent to $6.1 \%$ of the uncontrolled tower top displacement r.m.s.; while the hybrid and active systems reduce the displacement r.m.s of the top of the controlled tower to $3.7 \%$ and $4.7 \%$ of the displacement r.m.s. of the tower top without control, respectively.

Additionally, it can be observed that the passive control system presents better performance for a mass ratio around $7.5 \%$, which loses efficiency for higher mass ratios. However, the efficiency in the control of displacements of the tower top, for the hybrid and active systems, increases with the growth of the mass ratio until it reaches a horizontal asymptotic behavior from a mass ratio around $10 \%$. Nonetheless, for values of mass ratio with this value or higher, the feasibility of using the vibration absorber is hampered, if not impossible.
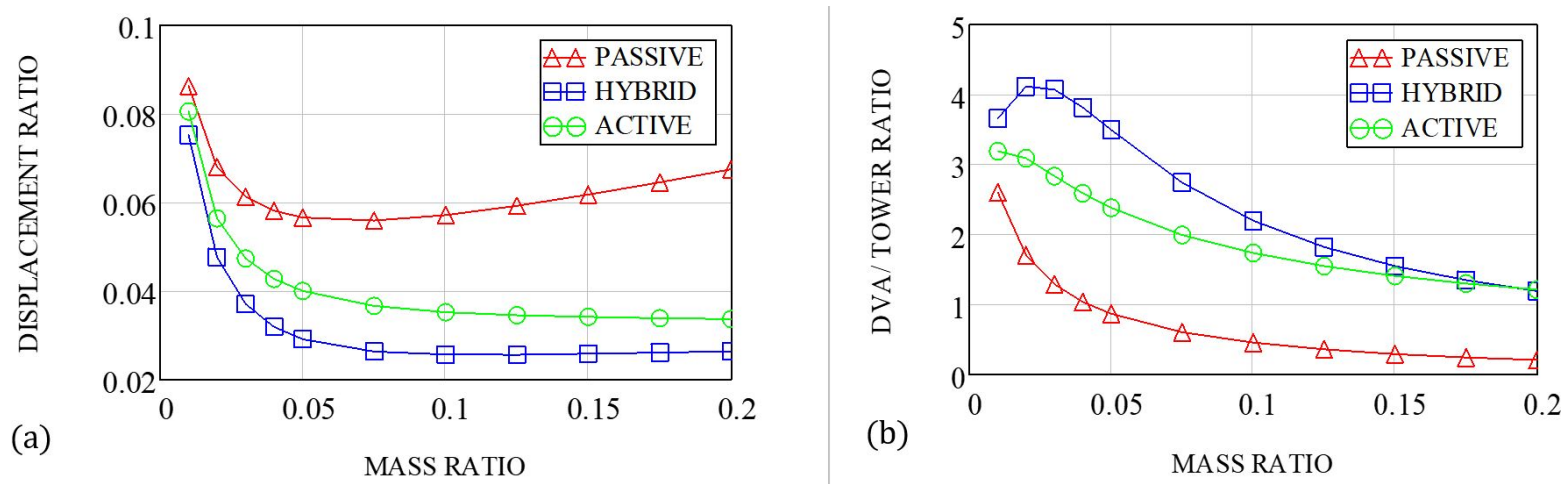

Figure 6: Displacement r.m.s. ratio: (a) tower top controlled and without control; (b) DVA and tower top controlled.

Another important aspect in this parametric analysis, which is comparative among the proposed control systems, refers to the energy required to achieve a certain level of control. It is possible to observe that the hybrid and active systems have similar behavior, both with respect to the tower response (Figure 6a) and with respect to the vibration absorber response (Figure 6b). In Figure 6a, the control behavior of the hybrid system is better than that of the active system because, on average, the r.m.s. displacement of the tower top is $24.3 \%$ lower when the hybrid control is used. In addition, Figure $6 \mathrm{~b}$ shows that, on average, the ratio between displacement r.m.s. of the absorber and tower top controlled in the hybrid system is $26.7 \%$ higher than that of the active system.

Finally, comparing the data of the graph of Figure 7, it is observed that the hybrid system requires a control force of a smaller magnitude in relation to a purely active system, because the curves have practically the same behavior, being only separated vertically, on average, by a value of $1.846 \mathrm{E} 4 \mathrm{~N}$. The previous comments establish and confirm some advantages of the hybrid control system in relation to the purely active system.

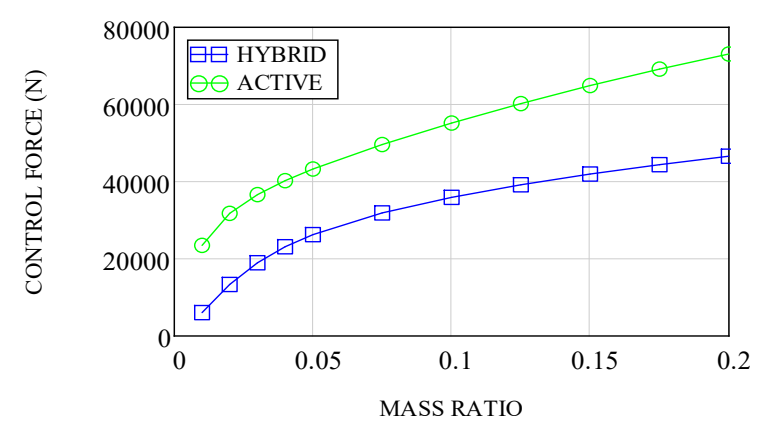

Figure 7: Control force r.m.s. applied to the top of the tower.

\subsection{Transient responses}

The harmonic excitation to which the tower is subjected was applied for a time of only $5 \mathrm{~s}$, from which the excitation ceases and the tower-DVA assembly vibrates freely (Figure 8 and Figure 9). This excitation simulates an intensity of a tipic wind gust. Table 4 shows the tower top maximum and r.m.s. displacements of uncontrolled and controlled systems; as well as the percentage reduction of such displacements. 
Table 4: Tower top displacement due to transient excitation.

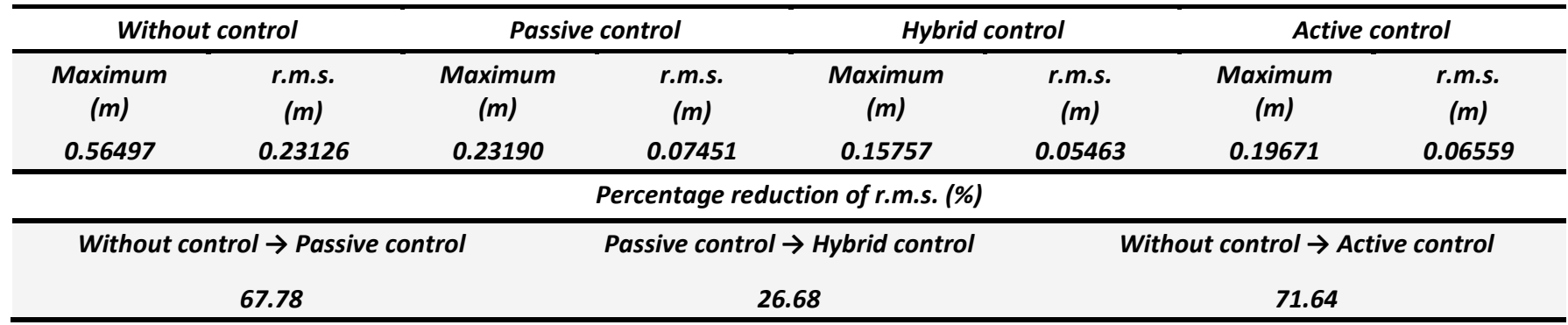

Figure 8 shows the graph of uncontrolled and passively controlled top of tower displacements, from which we can observe a high reduction of such displacement values; as shown in Table 4 . There is a reduction of 67.78 and $71.64 \%$ in the r.m.s. of the tower top displacement in relation to the uncontrolled case with the introduction of the passive and active DVA, respectively, in the tower structural system.

For comparisons of passively and hybridly controlled tower top displacements, the graphs of Figure 9a were plotted. It is observed that the hybrid system performs better than the purely passive system, reducing the r.m.s. of the tower top displacements by $26.68 \%$ in relation to the displacement of the top of the passively controlled tower. In addition, it is noticed that the vibration stops earlier (Figure 9a) and that the vibration peak is smaller (Table 4) when using the hybrid control system.

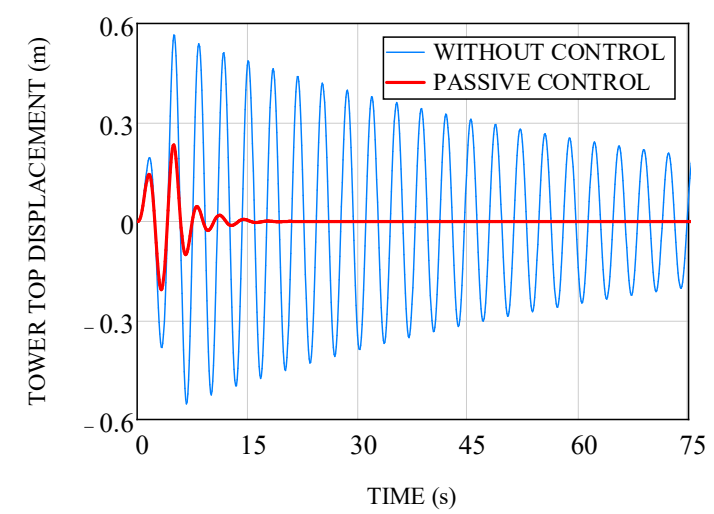

Figure 8: Tower top displacement without control and under passive control (transient excitation).
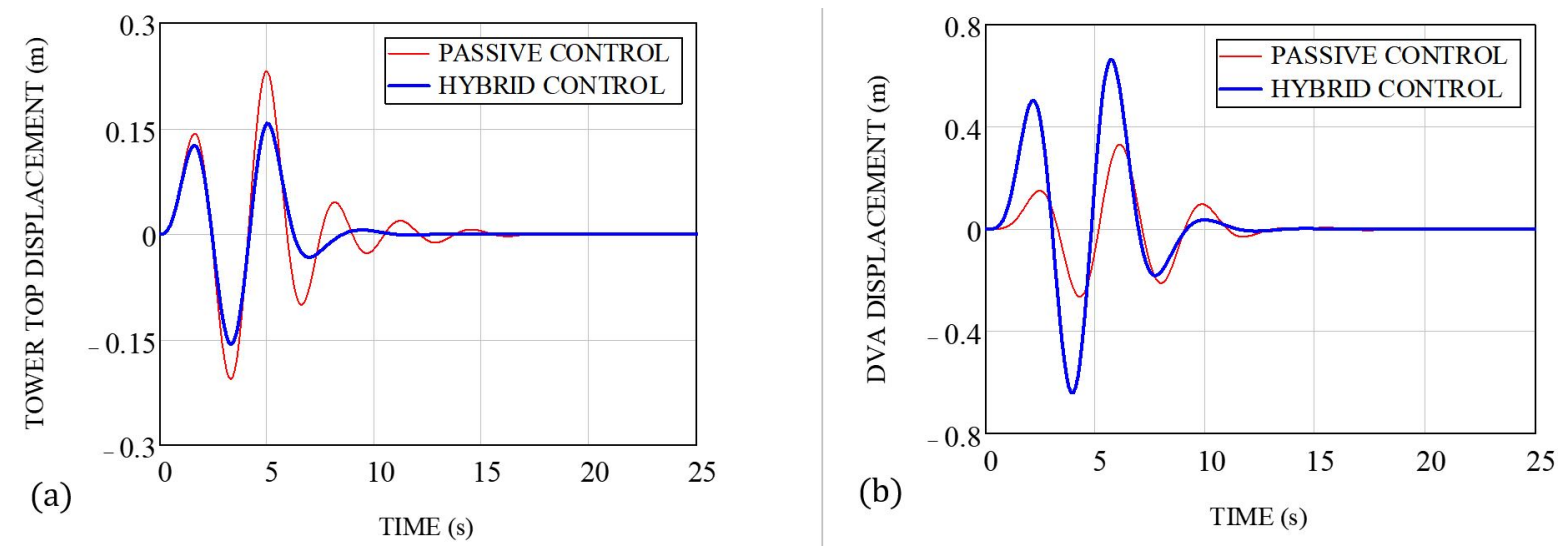

Figure 9: Displacements of the: (a) tower top and (b) DVA under passive and hybrid control (transient excitation).

It is shown in Figure 9b the graph of the displacements of the vibration absorber for tower equipped with passive and hybrid control. It should be noted that the absorber response becomes more rapid with the introduction of the actuators from the hybrid and active control systems, making these systems more suitable for situations where rapid control action is required for efficiency and robustness of the control system (as in the case of control of seismically excited structures). 
Finally, the graph of the control force acting on the dynamic vibration absorber with reaction at the top of the tower is shown in Figure 10. By means of the values of the control forces, one has an idea of the energy required for the control of the tower by the hybrid system. It is important to note that there is a lag (about $1.3 \mathrm{~s}$ ) between the peaks of the control force graphs (Figure 10) and the vibration absorber displacement (Figure 9b), so that the peak of the control force excites the vibration absorber, and it subsequently moves toward its displacement peak to control the structure of the tower.

\subsection{Steady-state responses}

In this section, the structure of the tower-DVA submitted to stacionary resonant harmonic excitation is analyzed, for which an analysis time of $100 \mathrm{~s}$ is used to calculate the r.m.s. values. Table 5 shows the tower top maximum and r.m.s. displacements of uncontrolled, passive and active controlled system.

In Figure 11 is shown the graph of the uncontrolled and passively controlled top of the tower, from which we can observe the high efficiency of the passive system in the control of the two 1st vibration modes (XY and YZ) of the tower, in view that the vibration absorber has been tuned to such frequencies. According to the data of Table 5, with the use of the passive and active systems, it is observed that there is a reduction of 93.87 and $95.26 \%$ in the r.m.s. of the tower top displacement in relation to the case without control, respectively.

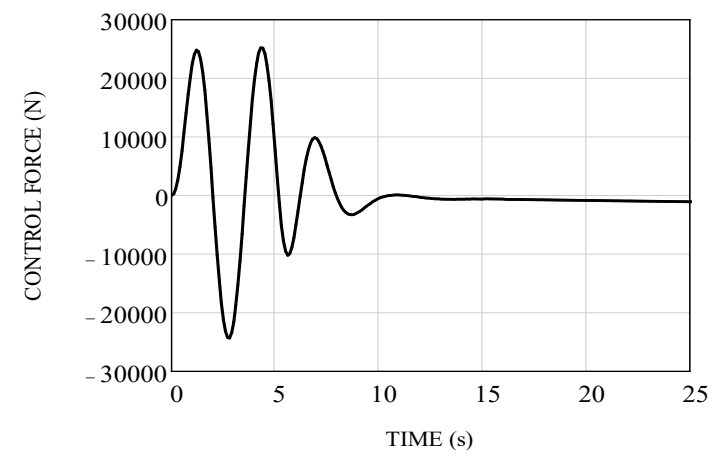

Figure 10: Control force applied by hydraulic actuadors (transient excitation).

Table 5: Tower top displacement due to permanent excitation.

\begin{tabular}{|c|c|c|c|c|c|c|c|}
\hline \multicolumn{2}{|c|}{ Without control } & \multicolumn{2}{|c|}{ Passive control } & \multicolumn{2}{|c|}{ Hybrid control } & \multicolumn{2}{|c|}{ Active control } \\
\hline Maximum (m) & $\begin{array}{l}\text { r.m.s. } \\
(m)\end{array}$ & $\operatorname{Maximum}(m)$ & $\begin{array}{c}\text { r.m.s. } \\
(m)\end{array}$ & Maximum (m) & $\begin{array}{c}\text { r.m.s. } \\
(m)\end{array}$ & Maximum (m) & $\begin{array}{c}\text { r.m.s. } \\
(m)\end{array}$ \\
\hline 6.02837 & 2.91768 & 0.25723 & 0.17884 & 0.15757 & 0.10828 & 0.19768 & 0.13833 \\
\hline \multicolumn{8}{|c|}{ Percentage reduction of r.m.s. (\%) } \\
\hline \multicolumn{3}{|c|}{ Without control $\rightarrow$ Passive control } & \multicolumn{2}{|c|}{ Passive control $\rightarrow$ Hybrid control } & \multicolumn{3}{|c|}{ Without control $\rightarrow$ Active control } \\
\hline \multicolumn{3}{|c|}{93.87} & \multicolumn{2}{|c|}{39.46} & \multicolumn{3}{|c|}{95.26} \\
\hline
\end{tabular}

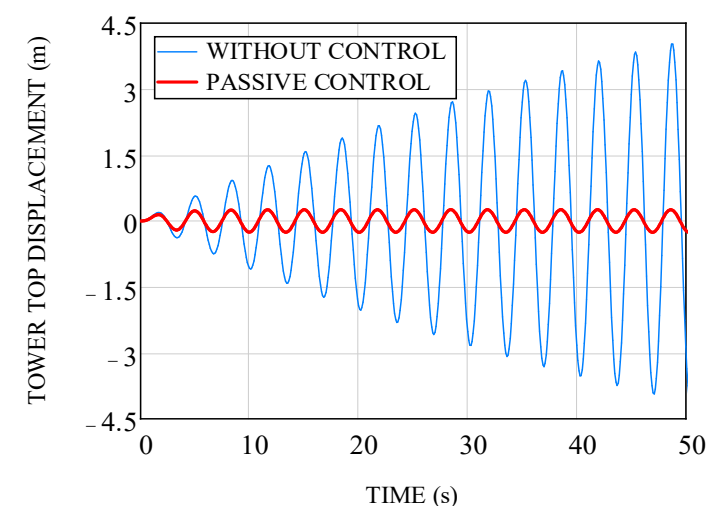

Figure 11: Tower top displacement without control and under passive control (stacionary excitation).

For the comparison of the passive and hybrid control systems, the graph of passively controlled and hybridly controlled tower displacements (Figure 12a) and Table 5 data are analyzed; in which it is possible to improve the 
performance of the control system, since the r.m.s. value of tower top displacements is reduced in $39.46 \%$ compared to the tower top displacements controlled passively.

In this way, the introduction of active control improves the robustness of the system in situations that require to refine/improve the vibration control. On the other hand, the passive control considerably reduces the displacements, so that the control system works well in situations of loss of electric power and, consequently, impossibility of actuation of the active system. However, when the structure is subjected to a detuned excitation in relation to the prevailing vibration frequency of the tower, the active control actuators begin to correct or improve/refine the behavior of the purely passive control, since the active control also works well for a frequency of excitation not tuned at any of the modal frequencies of the uncontrolled tower structure. Such performance of hybrid and active systems may become, in certain cases of practical application, indispensable for the proper functioning and safety of the tower structure and its users.
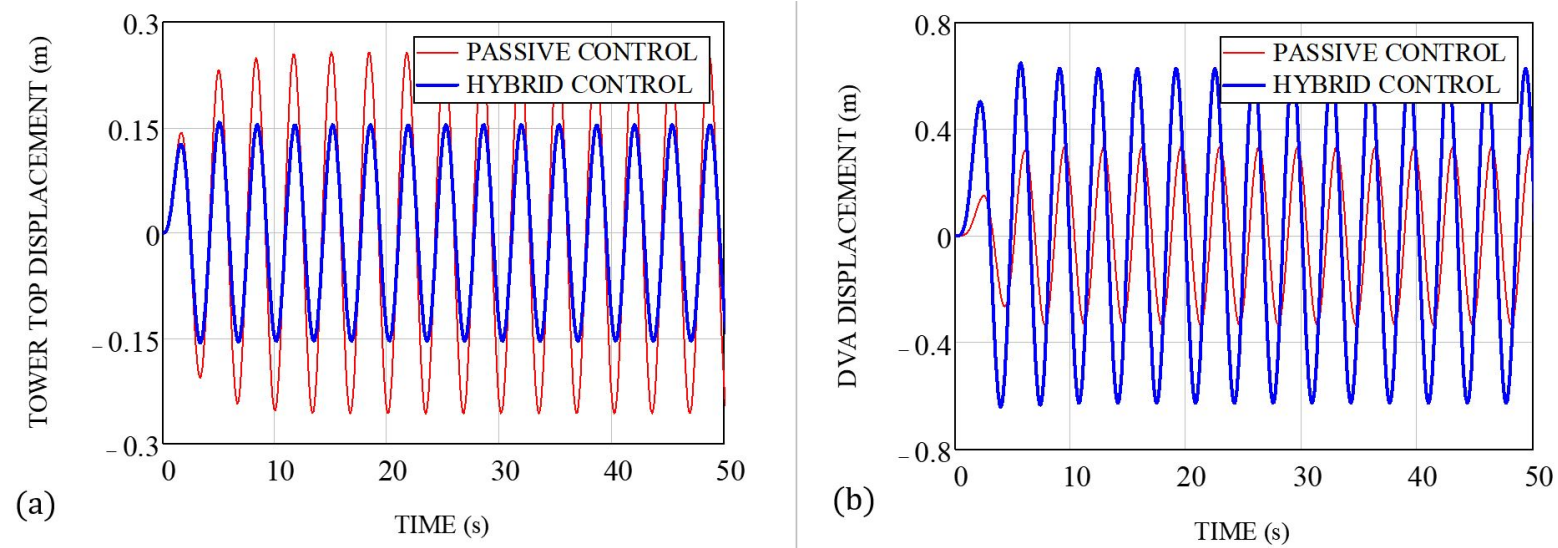

Figure 12: Displacements of the: (a) tower top and (b) DVA under passive and hybrid control (stacionary excitation).

Corroborating with the above findings, in Figure $12 \mathrm{~b}$ is shown the graph of the displacements of the vibration absorber for tower equipped with passive and hybrid control, in which the most effective action of the hybrid control is observed, since the dynamic vibration absorber responds more rapidly and significantly to the action imposed on the structure of the tower-DVA assembly. Finally, in Figure 13 is shown the graph of the control force exerted by the actuators that act on the dynamic vibration absorber and have a reaction at the top of the tower.

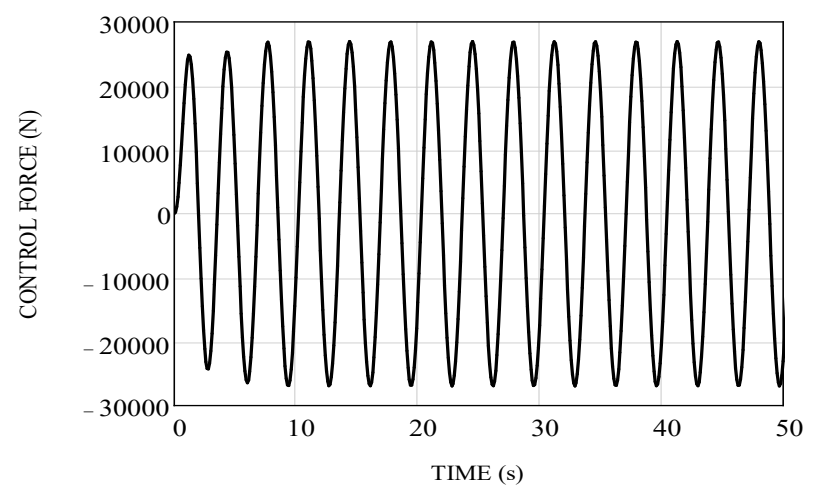

Figure 13: Control force applied by hydraulic actuadors (stacionary excitation).

The values of the control forces provide a perception of the energy required for the control of the tower by the hybrid system. In addition, the maximum control force (between 20.0 and $30.0 \mathrm{kN}$ ) is perfectly possible to be applied using an electronically controlled hydraulic pump with a working pressure between 1000 and 1500 bar, coupled to a piston with a cross-sectional area of $200 \mathrm{~cm}^{2}$ that highlights the technical feasibility of the proposed control system.

\subsection{DVA constructive model}

In this item, a sketch of the control mechanism developed in this study and based on the device proposed by Accioly (2006) is presented, according Figure 14. Then, the main components of this mechanism are described and enumerated, aiming to show the viability of design and execution of the vibration control system in tubular towers for wind turbines developed in this paper. 


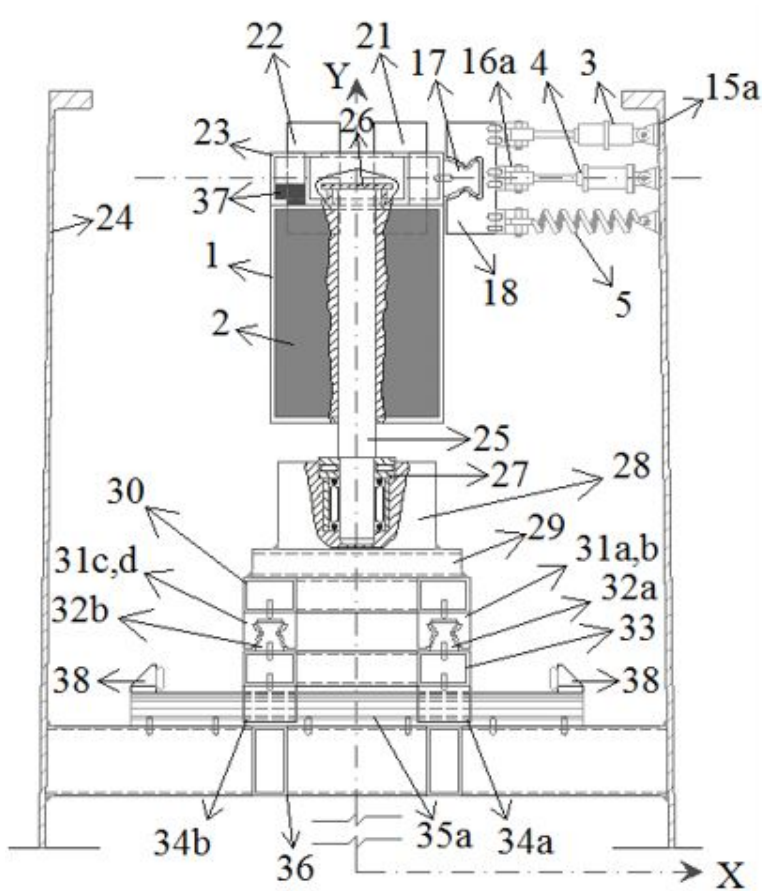

(a) XY-Plane.

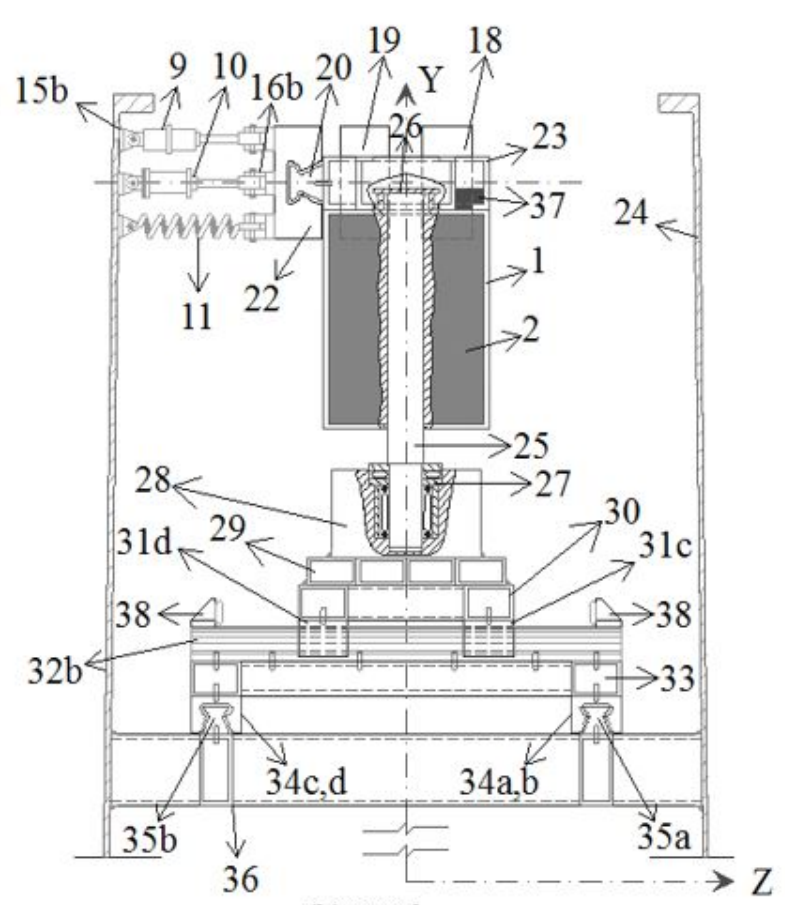

(b) YZ-Plane.

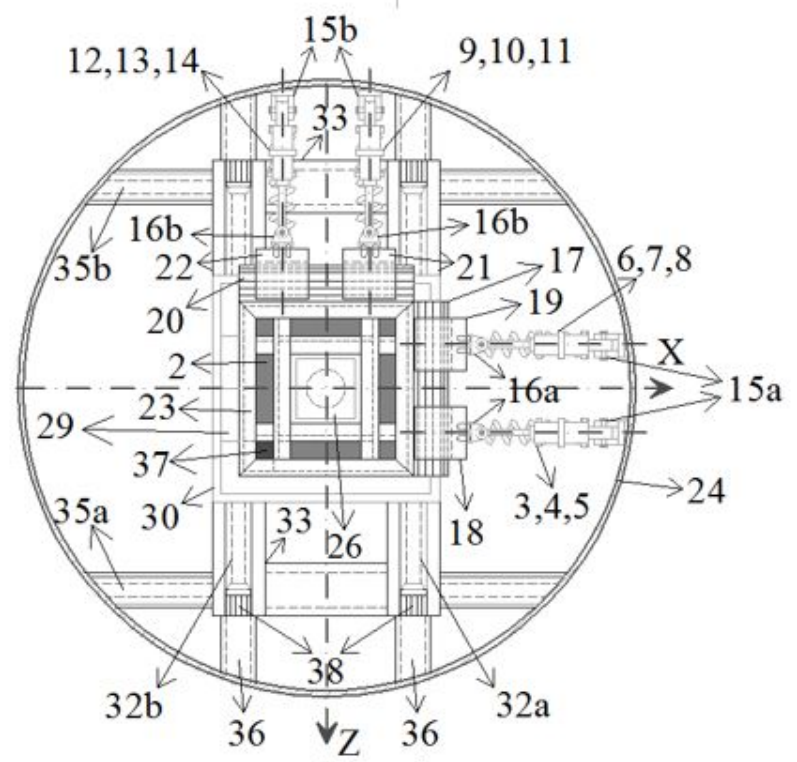

(c) XZ-Plane.

Figure 14: DVA constructive model (off-scale).

1 - steel housing for control mass support: external dimensions 1,00 x 1,00 x 2,25 m;

2 - lead mass control that fills the steel housing ( $n=1$ );

$\mathbf{3}, \mathbf{4}, \mathbf{5}, \mathbf{6}, \mathbf{7}, \mathbf{8}$ - viscous dampers (no 3 e 6), hydraulic actuators ( $n$ o 4 e 7) e linear springs (no 5 e 8 ) positioned in direction $\mathrm{X}$;

$9,10,11,12,13,14$ - viscous dampers ( $n$ o 9 e 12), hydraulic actuators ( $n$ o 10 e 13) e linear springs ( $n$ o 11 e 14) positioned in direction $Z$;

15a,b - hinges: six hinges ( $n$ ㅇ 15a: free rotation around the $Z$ axis) linking the components $n=3,4,5,6,7$, and 8 to the element $n=24$; and other six hinges ( $n$ ㅇ 15b: free rotation around the $X$ axis) joining the components $n=9,10,11,12$, 13 , and 14 to the element $\mathrm{n}$ 을 24

16a,b - hinges: six hinges ( $n$ o 16a: free rotation around the $Y$ axis) linking the components $n=3,4$, and 5 to the element $n=18$, and the components $n=6,7$, and 8 to the element $n=19$. And other six hinges ( $n$ o $16 b$ : free rotation 
around the $Y$ axis) joining the components $n=9,10$, and 11 to the element $n \circ 21$, and the components $n=12,13$ e 14 to the element no 22;

17, 18, 19 - linear slide guide positioned along the $Z$ axis: allows only the translation movement of the runners ( $n \circ 18$ e $n \circ 19$ ) in the longitudinal direction of the rail $n \circ 017$. The rail is fixed to the component $n \circ 23$, that, in turn, is fixed to the support housing ( $\mathrm{n}-1$ ) to the control mass ( $\mathrm{0}-2)$;

20, 21, 22 - linear slide guide positioned along the $X$ axis: allows only the translation movement of the runners ( $n$ 21 e $n=22$ ) in the longitudinal direction of the rail $n=20$. The rail is fixed to the component $n=23$, that, in turn, is fixed to the support housing ( $\mathrm{n}=1$ ) to the control mass ( $\mathrm{n}$ 을);

23 - structure for fixing rails: it is a reinforcement structure composed of metal bars with cold U-shaped sections, which serves as a support for the rails of linear slide guides ( $n \div 17$ e $n=20$ ). Then, this structure is attached to the control mass $\left(n^{\circ} 2\right)$ support housing ( $\left.n=1\right)$;

24 - tubular structure of the tower: where the hinges $n=15 a, b$ are fixed.

25 - king pin: metal shaft supporting the control mass ( $n$ - 2). The king pin is connected to the control mass by means of the component $n$ 을 26 ;

26 - king pin fixing system: set of metal plates fixed to the kingpin ( $n \circ 25)$ and to the control mass ( $n$ ㅇ 2);

27 - combined bearing: it provides rotation about the king pin's $Y$ axis ( $n=25)$ and the control mass ( $n$ ㅇ 2). Such a bearing is capable of withstanding axial and radial stresses. Although the control device designed in this work intends to control translations in the $X$ and $Z$ directions, the construction of the vibration absorber with this type of bearing allows the use of the same to the control of torsional rotations (rotation about the $Y$ axis);

28 - metal cylinder: which is attached to the component $n=29$, it has the function of behaving the combined bearing (no 27);

29 -metallic base: it is manufactured using tubes of rectangular cross-section and has the function of joining the metallic cylinder ( $n \div 28$ ) to the component $n=30$;

30 - movable upper metallic base: it is manufactured using tubes of rectangular section. At its upper part, it is fixed to the metallic base ( $n$ - 29) and, in the bottom part, is fixed to the components $n=31 a, b, c, d$;

31a,b,c,d; 32a,b - linear slide guide positioned along the $Z$ axis: only allows translation movement of the upper metallic base ( $n=30$ ) on the direction of the rails $n=32 a, b$. The latter are fixed to the component $n=33$. The components $31 a, b, c, d$ represent the stakes that are fixed to the element $n=30$;

33 - movable bottom metallic base: it is manufactured using tubes of rectangular section. At its upper part, it is fixed to the metallic base ( $n$ o 29) and, in the bottom part, is fixed to the components no $31 a, b, c, d$;

34a,b,c,d; 35a,b - linear slide guide positioned along the $X$ axis only allows translation movement of the bottom metallic base ( $n=33$ ) on the direction of the rails $n=35 a, b$. The latter are fixed to the component $n=36$. The components $34 a, b, c, d$ represent the runners that are fixed to the element $n=33$;

36 - rectangular tubular beam: on it are attached the rails $n=35 a, b$;

37 - counterbalance: formed by a lead mass used to balance the control mass ( $n-2)$, keeping the center of mass thereof coinciding with the center of the tubular tower mass;

38 - stopblock with rubber: safety device for limiting the movements of the DVA and for absorbing the impact of the runners $n=31 a, b, c, d$ on the rails $n=32 a, b$ and of the runners $n=34 a, b, c, d$ on the rails $n=35 a, b$. That is, it serves in the case of an unforeseen loading situation that would lead to the displacement of the runners beyond the limits of the rails.

\section{CONCLUSIONS}

After analysis developed in this paper, it is observed that the vibration absorbers proposed, both passive and hybrid, presented efficiency in the tower control vibration when the tower-absorber assembly is submitted to a harmonic action resonant to the 1st tower mode of vibration. Additionally, through the constructive scheme of the absorber exposed, the executive viability of the vibration control system for wide-scale horizontal axis wind turbine tubular towers is confirmed.

The results of the modal analysis performed for both the beam and shell finite element model are similar, especially in relation to the 1st vibration mode of the tower. Therefore, the model represented by beam FE can be used as representative of the tower dynamic behavior when it is submitted to the resonant excitations to its fundamental frequency. With this, the action of the floating part of the wind was modeled by resonant harmonic forces, considering the tendency that there is the excitation of the fundamental way of the tower. Since the increasing intensity of the wind forces with height relative to ground level, the increase of the horizontal displacements to the tower with respect to the 
height in the 1st mode of vibration and the mass concentrated in the top (nacelle), of the same order of magnitude of the tower mass, are factors that contribute to excitation of the 1st mode of vibration of the tower.

Three types of absorbers were then comparatively studied: tuned mass damper (TMD), active mass damper (AMD) and hybrid mass damper (HMD). The HMD, the main contribution of this paper, reached excellent levels of vibration reduction for the tower subjected to harmonic actions, in a transient and permanent (stationary) regime, resonating with the first vibration mode of the structure without absorber.

In view of the obtained results, it is verified that the purely passive system is quite efficient in the control of vibrations of the excited tower according to the 1st vibration mode for which the absorber is tuned. Hybrid and active systems have been able to significantly improve passive system performance. It can be noted that the absorber response becomes faster with the introduction of hydraulic actuators of the hybrid control system, making this system suitable for situations where rapid control action is required for effectiveness and robustness of the system.

It is concluded, therefore, that the results of this work involve contributions of immediate practical interest, since the research develops subsidies for structural analysis and vibration control of the towers for multi-megawatt wind turbines to be implanted in Brazil considering the recent growth of the country's wind potential.

Author's Contributions: Conceptualization, DM Lima and PA López-Y; Formal analysis, DM Lima and MA Pereira; Methodology, DM Lima and PA López-Y; Software, DM Lima and MA Pereira; Supervision, DM Lima and PA López-Y; Validation, DM Lima and PA López-Y; Visualization, DM Lima and MA Pereira; Writing - original draft, DM Lima and MA Pereira; Writing - review \& editing, DM Lima.

Editor: Pablo Andrés Muñoz Rojas.

\section{References}

Abeeólica (2018). Energia eólica ultrapassa marca de 14 GW de capacidade instalada. Notícias, Agência ABEEólica. Available at: http://abeeolica.org.br/.

Accioly, M. M. L. (2006). Aplicação de métodos de controle ótimo à redução de vibrações em edifícios submetidos à ação de cargas dinâmicas. Ph.D. Thesis (in Portuguese), Federal University of Paraíba, Brazil.

Asibor, A. I., Garcia, J. R., Ramos, M. C., Silva, E. C. M., Araújo, A. M., (2015). Wind turbine performance and loading calculations using aeroelastic modelling. In: 23 th International Congress of Mechanical Engineering, ABCM, Rio de Janeiro. ANSYS release 14.5 (2012). Swanson Analysis Systems Inc.

Associação Brasileira de Normas Técnicas (ABNT), NBR 6123: 1988, Forças devidas ao vento em edificações, Rio de Janeiro, 1988.

Atlas..., (2017). Atlas eólico e solar de Pernambuco. Available at: http://www.atlaseolicosolar.pe.gov.br/.

Blevins, R. D. (2001). Flow-induced vibration, 2nd Edition, Krieger Publishing Company, Malabar.

Burton, T., Jenkins, N., Sharpe, D., Bossanyi, E. (2011). Wind energy handbook. 2nd Edition, John Wiley \& Sons, Chichester.

Chopra, A. K. (2012). Dynamics of structures: theory and applications to earthquake engineering. 4nd Edition, Practice Hall.

Colherinhas, G. B., Morais, M. V. G.; Shzu, M. A. M.; Ávila, S. M., (2015). Genetic optimization of tower vibrations with pendulum TMD. In: 36th Ibero-Latin American Congress on Computational Methods in Engineering, Rio de Janeiro.

Cook, R. D., Malkus, D. S., Plesha, M. E., Witt, R. J. (2002). Concepts and applications of finite element analysis. 4nd edition, John Wiley \& Sons, Madison.

Clough, R. W. and Penzien, J. (2003). Dynamics of structures. 3rd edition, Computers \& Structures, Berkeley.

Den Hartog, J. P. (1947). Mechanical vibrations. 3rd edition, McGraw-Hill, New York.

Franco, M. (1993). Direct Along-wind Dynamic Analysis of Tall Structures. Boletim Técnico da Escola Politécnica, EPUSP, São Paulo.

GWEC (2018). Global Wind Energy Council. Global statistics. Brussels. Available at: http://gwec.net/global-figures/graphs/.

Hau, E. (2006). Wind turbines: fundamentals, technologies, application, economics. 2nd. Edition, Springer, Munich. 
Housner, G. W., Bergman, L. A., Caughey, T. K., Chassiakos, A. G., Claus, R. O., Masri, S. F., Skelton, R. E., Soong, T. T., Spencer, B. F., Yao, J. T. P., (1997). Structural control: past, present and future. Journal of Engineering Mechanics 123 (9): $897-971$.

$\mathrm{Hu}, \mathrm{Y} ., \mathrm{He}, \mathrm{E}$. , (2017). Active structural control of a floating wind turbine with a stroke-limited hybrid mass damper. Journal of Sound and Vibration 410: 447-472.

Humar, J. L. (2002). Dynamics of Structures. 2nd edition, A.A. Balkema Publishers, Ottawa.

Juárez, A. A., Araújo, A. M., Rohatgi, J. S., Oliveira Filho, O. D. Q., (2014). Development of the wind power in Brazil: political, social and technical issues. Renewable and Sustainable Energy Reviews 39: 828-834.

Junkins, J. L. and Kim, Y. (1993). Introduction to dynamics and control of flexible structures. American Institute of Aeronautics and Astronautics, Washington, D.C.

Kwakernaak, H. and Sivan, R. (1972). Linear optimal control systems. Wiley \& Sons, New York.

Lange, H. and Elberg, C., (2018). Development of soft towers for wind turbines. In: Wind Turbine Towers, Bremen.

Lackner, M. A.; Rotea, M. A., (2011). Passive structural control of offshore wind turbines. Wind Energy 14: 373-388.

Lima, D. M. (2018). Análise da estabilidade elástica, análise dinâmica e controle de vibração em torres tubulares de aço para aerogeradores de eixo horizontal. Ph.D. Thesis (in Portuguese), Federal University of Pernambuco, Brazil.

Lima, D.M.; López-Yánez, P. A.; Silva, J. W., (2018). Análise da estabilidade elástica em torres tubulares de aço para aerogeradores de eixo horizontal. Revista da Estrutura de Aço 7 (2): 100-119.

Lyapunov, A. M., (1992). The general problem of the stability of motion. International Journal of Control 55 (2): $531-773$.

Manwell, J. F., McGowan, J. G., Rogers, A. L. (2009). Wind energy explained: theory, design and application. 2nd Edition, John Wiley \& Sons, Chichester.

Mathcad 15.0 M020 (2012). PTC software.

Meirovitch, L. (1990). Dynamics and control of structures. JohnWiley \& Sons, New York.

Menezes, E. J. N.; Araújo, A. M.; Rohatgi, J. S.; Foyo, P. M. G., (2018). Active load control of large wind turbines using state-space methods and disturbance accommodating control. Energy 150: 310-319.

Moutinho, C. M. R. (2007). Controlo de vibrações em estruturas de engenharia civil. Ph.D. Thesis (in Portuguese), Porto University, Portugal.

Murtagh, P. J., Ghosh, A., Basu, B., Broderick, B. M., (2008). Passive control of wind turbine vibrations including blade/tower interaction and rotationally sampled turbulence. Wind Energy 11: 305-317.

Ogata, K. (1997). Modern control engineering. 3rd edition, Prentice Hall, United States of America.

Rao, S. (2011). Mechanical vibrations. 5nd edition, Prentice Hall, United States of America.

Siemens (2014). Siemens D3 platform - 3.0-MW and 3.2 - MW direct drive wind turbines: Reduced complexity, increased profitability. Erlangen, Germany. Avalaible at: https://www.energy.siemens.com/br/pool/hq/powergeneration/renewables/wind-power/platform20brochures/D3\%20Onshore\%20brochure_ENGLISH_Apr2014_WEB.pdf.

Shzu, M. A. M., Morais, M. V. G., Del Prado, Z. J. G., Ávila, S. M., (2015). Finite element analysis of a wind turbine tower with a pendulum tuned mass damper. In: 17th International Symposium on Dynamic Problems of Mechanics, Natal.

Stewart, G. M., Lackner, M. A., (2013). Offshore wind turbine load reduction employing optimal passive tuned mass damping systems. IEEE Transactions on Control Systems Technology 21(4): 1090-1104.

Stewart, G. M., Lackner, M. A., (2014). The impact of passive tuned mass dampers and wind-wave misalignment on offshore wind turbine loads. Engineering Structures 73: 54-61.

Tong, X., Zhao, X., Zhao, S., (2015). Load reduction of a monopole wind turbine tower using optimal tuned mass dampers. International Journal of Control 90: 1283-1298.

Yoshida, P. E., (2006). Wind Turbine Tower Optimization Method Using Genetic Algorithm. Wind Engineering 30(6): $453-470$.

Zuo, H., Bi, K., Hao, H., (2017). Using multiple tuned mass dampers to control offshore wind turbine vibrations under multiple hazards. Engineering Structures 141: 303-315. 